\title{
Nutritional intake of various groups of Flemish vegetarians
}

by

Deriemaeker $\mathrm{P}^{1}$, Alewaeters $\mathrm{K}^{1}$, Hebbelinck $\mathrm{M}^{1}$, Clarys $\mathrm{P}^{1}$

\begin{abstract}
Background

The most recent national nutritional survey (2004) indicates that $1.2 \%$ of the Flemish population follows a vegetarian diet. Information on nutritional intake in vegetarians in this population is scarce.
\end{abstract}

Objective

The aim of the present study is to describe the nutritional intake and dietary adequacy of various groups of Flemish vegetarians.

Materials and methods

Nutritional intake was assessed in various vegetarian groups from different study designs: young children (aged 1 to $10 \mathrm{y} ; n=27$ ) (Group 1), adolescents and adults (aged 11 to $32 \mathrm{y}$; $n=50)$ (Group 2), college students (aged 18 to $24 y$; $n=24$ ) (Group 3), life-long vegetarians (aged 14 to $71 \mathrm{y}$; $n=36$ ) (Group 4) and adults (aged 20 to 98; $n=106$ ) (Group 5). Additionally, blood samples were collected and analysed in groups 3 and 4. Comparisons were made with standard references or with omnivores (Group 3).

Results

Nutritional intake was found to be close to the Belgian RDA. However, all groups showed a number of outliers with an intake of some nutrients above or below the RDAs. Blood biochemistry showed low cholesterol, iron and vitamin B12 levels in vegetarians when comparing respectively with omnivores pairs (Group 3) and with reference values (Group 4).

Conclusions

Data collected in Flemish vegetarians indicate that a vegetarian diet may be adequate. However, the outliers in all groups show that proper dietary planning is advisable.

\section{Keywords}

Nutritional intake, dietary adequacy, Flemish vegetarians

\footnotetext{
1 Vrije Universiteit Brussel, Faculty of Physical Education and Physical Therapy, Department of Biometry and Biomechanics, Brussels, Belgium

pderiema@vub.ac.be
} 


\section{Introduction}

The influence of nutritional practices and physical activity on health outcomes are well documented (1). The most recent National Nutritional Survey (2004) revealed a poor eating pattern and lack of physical activity for the Belgian, including the Flemish, population $(2,3)$. The survey indicated a high intake of protein sources (160g/day; RDA: 100g/day). The protein sources were meat ( $119 \pm 38 \mathrm{~g} /$ day), fish ( $24 \pm 12 \mathrm{~g}$ day), eggs ( $10 \pm 8 \mathrm{~g} /$ day $)$ and vegetarian products ( $5 \mathrm{~g} /$ day of seeds, nuts, pulses, tofu, quorn and tempeh). Fruit and vegetable intakes were very low (respectively $118 \mathrm{~g} /$ day and $138 \mathrm{~g} /$ day). The reported macronutrient distribution was not in accordance with the reference values proposed by the Health Council (4): $16.3 \mathrm{E} \%$ protein (reference 10 to $15 \mathrm{E} \%$ ), 45.7E\% carbohydrate (reference minimum 55E\%) and $37.9 \mathrm{E} \%$ fat (reference maximum $30 \mathrm{E} \%$ ). The survey indicated only $1.2 \%$ of the sample as vegetarians (2).

Nutritional habits and dietary patterns show country-specific (5-7) and regional variations (8). One can assume that vegetarian food patterns may also follow more or less a country- and region-specific variation. Data on nutritional intake of European vegetarians are available from Germany, United Kingdom, Sweden and France (9-15). To our knowledge only 2 studies describing nutritional intake (amongst other health related aspects) on Flemish vegetarians have been published $(16,17)$. Since there is a growing interest in healthy diets and vegetarian nutrition, particularly in the older (5-7) and the younger age groups $(2,18)$, it is believed that a survey of the available data on the Flemish vegetarians would contribute to the present knowledge of this dietary lifestyle.

The purpose of this study was to investigate the nutritional intake and adequacy of different groups of Flemish vegetarians using data from different study designs.

\section{Methods}

Statistical information on Flemish vegetarians was drawn from the data on Flemish vegetarians collected during different studies between 1994 to 2005 in the research unit 'Fitness and Health' of the Department Biometry and Biomechanics (BIOM) of the Vrije Universiteit Brussel (VUB). Covering different stages of the life span, published nutritional intake data $(16,17)$ and unpublished nutritional intake data from our research unit will be briefly described and discussed with regard to the age groups of the original research designs (Table 1). Nutritional intake data were collected using food records (7-day or 3-day diaries). All preprinted diaries contained an instruction manual including portion size or weight or volume of common household measures. Volunteers were asked to weigh the consumed food items when possible or to indicate portion or size of the consumed food items.

Vegetarianism was defined as abstinence of meat, game, poultry, and fish in the diet. 
Table 1. Description of the various groups

\begin{tabular}{llllll}
\hline & $\begin{array}{l}\text { Year of data } \\
\text { collection }\end{array}$ & $\begin{array}{l}\text { Age when entering } \\
\text { the study (y) }\end{array}$ & $\mathrm{n}$ & Assessment method & Blood sample \\
\hline Group 1 & 1994 & 1 to $10 \mathrm{y}$ & 27 & 7-day food record diary & No \\
Group 2 & 1994 & 7 to $32 \mathrm{y}$ & 50 & 7-day food record diary & No \\
Group 3 & 1997 & 18 to $25 \mathrm{y}$ & 24 & 7-day food record diary & Yes \\
Group 4 & 1999 & 14 to 71 y & 36 & 7-day food record diary & Yes \\
Group 5 & 2005 & 20 to 71 y & 106 & 3-day food record diary & No \\
\hline
\end{tabular}

Group 1: young children ( 1 to $10 \mathrm{y} ; \mathrm{n}=27$ )

Thirty-five families with vegetarian children were contacted in health food shops. Their parents completed the 7-day food diary. After exclusion of 9 semi-vegetarians (reporting intake of meat and/or fish in the nutrition diary), 27 subjects with a complete 7-day food diary remained. Age specific cut-offs were used indicating the number of subjects under the $80 \%$ or above the $120 \%$ limit of the Belgian RDA for energy, macro- and micronutrients (19).

Group 2: adolescents and adults (11 to $32 \mathrm{y} ; \mathrm{n}=50)(20)$

Subjects (or their parents) were recruited in the Flemish region of Belgium by advertising in health food shops. Dietary analysis was performed using a 7-day food diary completed by the volunteers, sometimes assisted by their parents. Since the main aim of that study was to describe the growth and development of vegetarians, in the original design data were analysed according to the following categories: male $(n=9)$, female $(n=20)$ adolescents $(11-19.9$ $y)$ and male $(n=7)$ and female $(n=14)$ adults $(20-32 y)$.

Group 3: college students (18 to $25 \mathrm{y} ; \mathrm{n}=24)(16)$

A total of 24 vegetarian students (14 males and 10 females, mean age 20.6 \pm 2.1 and $19.8 \pm 1.4$ y, respectively) were compared with "matched pairs" of omnivorous students (14 males and 10 females, mean age $20.9 \pm 2.7$ and $20.5 \pm 1.4 \mathrm{y}$, respectively).

Every vegetarian student was asked to find an omnivorous pair. Matching was done for sex, age, BMI, physical activity, smoking habits and alcohol use. Dietary intake was assessed using 7-day food diaries. Comparisons were made with RDAs (4) and with the group of matched omnivores.

Blood samples were collected after an overnight fast and analysed for iron, calcium, zinc, vitamin B12, vitamin B9, cholesterol, HDL-cholesterol and LDL-cholesterol in the clinical biology laboratory of the university hospital of the Vrije Universiteit Brussel, following validated standard procedures. 
Group 4: lifelong vegetarians (vegetarian since birth) (14 to 71 y of age; $n=36)$ (17)

A total of 36 lifelong vegetarians volunteered in this study (23 women, 13 men), ranging between 14 and 71 y (median age 20.3 y). Dietary assessment was carried out using a 7-day food diary. Blood samples were collected following the same procedures as mentioned for Group 3.

Group 5: adults (20 to 71 y of age; $n=106$ )

Subjects were recruited through advertising in health food shops, in magazines, on the website of vegetarian and animal rights organisations, and through word of mouth. Criteria for inclusion were being a vegetarian (for at least 1 year) and being at least 18 years of age. The first objective of the design was to collect health related and lifestyle variables in vegetarians (21). Out of the 405 respondents 106 vegetarians completed the 3-day food diary (35 men, 22-65 y; 71 women, 20-71 y). Using a 3-day physical activity diary, individual energy requirements were calculated taking into account the physical activity level (PAL), body weight and age. BMI was calculated using self-reported values of body weight and height.

Analyses of the diaries of all groups were carried out using the BECEL software programme, based on the most recent Belgian National Food Composition Tables (NUBEL 1996-2004), (22).

Statistical comparisons were performed using SPSS. For the comparisons of our data with reference values one sample t-tests were applied. To compare the vegetarian with the omnivorous subjects an independent sample t-test was used. Significance level was set at 0.05.

All procedures used were approved by the ethical committee of the Vrije Universiteit Brussel. Informed consent was obtained from all subjects (or their parents).

\section{Results}

Group 1 - young children

In the young children total energy intake did not reach the $80 \%$ tolerance limit for 4 out of 13 subjects from the youngest (1.0-3.9 y) group, and for half of the subjects of the middle (4.0$6.9 \mathrm{y}$ ) group (3 out of 6), and half of the subjects from the oldest (7.0-9.9 y) group (4 out of 8). Two subjects from the youngest group and 1 subject from the oldest group had a total energy intake above the $120 \%$ tolerance limit (Tables 2 and 3).

As to the different macronutrients, a substantial number of subjects had intakes under the $80 \%$ or above the $120 \%$ tolerance limit (all groups together). Seven subjects had a protein intake under the $80 \%$ tolerance limit, whilst 4 subjects had a protein intake above the $120 \%$ tolerance limit. All but one subject had a carbohydrate intake above the $120 \%$ tolerance limit. Fat intake was in almost half of the subjects below the $80 \%$ tolerance limit while only 1 subject had an intake above the $120 \%$ tolerance limit. 
Table 2. Macronutrient intake of the different groups studied

\begin{tabular}{|c|c|c|c|c|}
\hline \multirow[t]{2}{*}{$\begin{array}{l}\text { Age } \\
\text { (years) }\end{array}$} & \multirow[t]{2}{*}{$\begin{array}{l}\text { Total Energy } \\
\text { (MJ/day) }\end{array}$} & \multirow{2}{*}{$\begin{array}{l}\text { Protein } \\
(\mathrm{E} \%) \\
\text { Ref } 10-15\end{array}$} & \multirow{2}{*}{$\begin{array}{l}\text { Fat } \\
(\mathrm{E} \%) \\
\text { Ref } 15-30\end{array}$} & \multirow{2}{*}{$\begin{array}{l}\text { Carbohydrate } \\
\text { (E\%) } \\
\text { Ref 55-75 }\end{array}$} \\
\hline & & & & \\
\hline \multicolumn{5}{|l|}{ Group 1} \\
\hline 1 to $3.9(n=13)$ & $4.5 \pm 1.3(4.7)^{1}$ & & & \\
\hline 4 to $6.9(n=6)$ & $5.2 \pm 0.9(6.7)^{1}$ & & & \\
\hline 7 to $9.9(n=8)$ & $6.4 \pm 1.9(7.6)^{1}$ & & & \\
\hline TOTAL $(\mathrm{N}=27)$ & & $13 \pm 3$ & $31 \pm 4$ & $56 \pm 6$ \\
\hline \multicolumn{5}{|l|}{ Group 2} \\
\hline 11 to $19.9 \mathrm{M}(\mathrm{n}=9)$ & $8.0 \pm 1.5(9.9)^{1}$ & & & \\
\hline 11 to $19.9 F(n=20)$ & $6.4 \pm 1.8(8.5)^{1}$ & & & \\
\hline 20 to $32 M(n=7)$ & $8.2 \pm 2.2(12.1)^{1}$ & & & \\
\hline 20 to $32 F(n=14)$ & $6.7 \pm 2.2(9.0)^{1}$ & & & \\
\hline TOTAL $(\mathrm{N}=50)$ & & $12 \pm 2$ & $32 \pm 7$ & $56 \pm 7$ \\
\hline \multicolumn{5}{|l|}{ Group 3} \\
\hline 18 to $25 M(n=14)$ & $11.2 \pm 2.4(12.1)^{1}$ & & & \\
\hline 18 to $25 F(n=10)$ & $8.8 \pm 2.2(9.0)^{1}$ & & & \\
\hline TOTAL (N=24) & & $12 \pm 3$ & $30 \pm 5$ & $56 \pm 7$ \\
\hline \multicolumn{5}{|l|}{ Group 4} \\
\hline 14 to $71 \mathrm{M}(\mathrm{n}=13)$ & $10.6 \pm 3.2(10.5)^{1}$ & & & \\
\hline 14 to $71 F(n=23)$ & $8.7 \pm 2.4(8.4)^{1}$ & & & \\
\hline TOTAL $(\mathrm{N}=36)$ & & $13 \pm 3$ & $34 \pm 8$ & $51 \pm 7$ \\
\hline \multicolumn{5}{|l|}{ Group 5} \\
\hline 22 to $65 M(n=35)$ & $9.8 \pm 2.9(13.7 \pm 2)^{2}$ & & & \\
\hline 20 to $71 F(n=71)$ & $8.3 \pm 2.3(9.8 \pm 1)^{2}$ & & & \\
\hline TOTAL $(\mathrm{N}=106)$ & & $13 \pm 2$ & $29 \pm 7$ & $55 \pm 8$ \\
\hline
\end{tabular}

Remark: Alcohol intake was minimal and not reported in this table

${ }_{1}^{1}$ RDA: Belgian Recommended Daily Allowances (4)

${ }^{2}$ Calculated with Physical Activity Level 
Regarding the minerals and vitamins analysed we noticed a substantial number of subjects with intakes below the $80 \%$ tolerance limit for iron $(n=9)$, calcium $(n=10)$ vitamins $B 6(n=8)$, B12 $(n=6)$ and B9 $(n=9)$ (Table 3).

Table 3. Number of subjects under $80 \%$ or above $120 \%$ of the RDA

\begin{tabular}{llll}
\hline & $\begin{array}{l}1.0 \text { to } 3.9 \text { years } \\
(\mathrm{n}=13)\end{array}$ & $\begin{array}{l}4.0 \text { to } 6.9 \text { years } \\
(\mathrm{n}=6)\end{array}$ & $\begin{array}{l}7.0 \text { to 9.9 years } \\
(\mathrm{n}=8)\end{array}$ \\
\hline Total energy & $4(1)$ & $3(0)$ & $4(1)$ \\
Protein & $2(4)$ & $1(0)$ & $4(0)$ \\
Fats & $4(1)$ & $3(0)$ & $5(0)$ \\
Carbohydrate & $0(12)$ & $0(6)$ & $0(8)$ \\
Fibre & $2(0)$ & $1(0)$ & $2(0)$ \\
Ca & $5(0)$ & $1(0)$ & $4(0)$ \\
Iron & $3(0)$ & $3(0)$ & $3(0)$ \\
Vit A & $2(0)$ & $1(0)$ & $1(0)$ \\
Vit B1 & $4(0)$ & $3(0)$ & $4(0)$ \\
Vit B2 & $2(0)$ & $1(0)$ & $5(0)$ \\
Vit B6 & $4(0)$ & $2(0)$ & $2(0)$ \\
Vit B9 & $4(0)$ & $3(0)$ & $2(0)$ \\
Vit B12 & $1(0)$ & $1(0)$ & $4(0)$ \\
Vit C & $2(0)$ & $1(0)$ & $1(0)$ \\
\hline
\end{tabular}

Values between brackets are the number of subjects above the $120 \%$ tolerance limit (Group 1)

Group 2 - adolescents and adults

In the adolescents and adults mean total energy intake of the different age groups did not reach their respective reference value (Table 2).

For the group as a whole $(n=50), 10$ subjects had a contribution of protein below the lower limit of $10 \mathrm{E} \%$ while 6 had an intake above the upper limit of $15 \mathrm{E} \%$. As to carbohydrate 21 subjects did not reach the recommended $55 \mathrm{E} \%$ whilst for fat intake 31 subjects had an intake above the upper limit of 30E\%. The mean (all subjects) cholesterol intake of $186 \pm 135$ $\mathrm{mg} /$ day was far below the maximum allowed intake of $300 \mathrm{mg} / \mathrm{day}$. Mean fibre intake was close to the age-specific recommendation for the 4 age groups of Group 2.

The mean intake of calcium, iron, magnesium and zinc was low (Table 4). None of the female young adults reached the lower intake limits for calcium, iron and magnesium. None of the subjects reached the lower intake limit for zinc. A high vitamin C and B1 intake was noticed in the 4 groups while vitamin B2 and B6 intakes were low (Table 4): none of the male young adults reached the limit for B2 and B6 while only 3 female young adults reached the intake for vitamin B2 and 1 for vitamin B6. 
Table 4. Vitamins and minerals intake in vegetarian adolescents and adults (11 to $32 \mathrm{y} ; \mathrm{n}=50$ ) (Group 2)

\begin{tabular}{|c|c|c|c|c|c|}
\hline Age group & & $11-19.9$ y & $11-19.9 y$ & $20-32$ y & $20-32$ y \\
\hline & $\mathrm{RDA}^{1}$ & $M^{2}(n=9)$ & $F^{2}(n=20)$ & $M^{2}(n=7)$ & $F^{2}(n=14)$ \\
\hline Calcium (mg/day) & $900-1200$ & $710 \pm 214$ & $734 \pm 314$ & $661 \pm 307$ & $751 \pm 362$ \\
\hline Iron (mg/day) & $8-21$ & $9.3 \pm 2.9$ & $8.7 \pm 3.2$ & $10.9 \pm 4.5$ & $10.1 \pm 3.9$ \\
\hline Magnesium (mg/day) & $330-420$ & $223 \pm 88$ & $215 \pm 54$ & $246 \pm 31$ & $204 \pm 52$ \\
\hline Zinc (mg/day) & $7-9.5$ & $3.7 \pm 1.0$ & $4.1 \pm 0.9$ & $4.8 \pm 1.4$ & $4.7 \pm 1.5$ \\
\hline Vit C (mg/day) & $65-70$ & $115 \pm 51$ & $110 \pm 48$ & $77 \pm 35$ & $117 \pm 71$ \\
\hline Vit B1 (mg/day) & $0.9-1.1$ & $2.2 \pm 1.3$ & $2.4 \pm 2.2$ & $2.0 \pm 1.3$ & $1.4 \pm 2.2$ \\
\hline Vit B2 (mg/day) & $1.2-1.6$ & $1.2 \pm 0.8$ & $1.2 \pm 1.3$ & $1.0 \pm 0.9$ & $1.0 \pm 0.3$ \\
\hline Vit B6 (mg/day) & $1.1-1.7$ & $1.2 \pm 0.2$ & $0.9 \pm 0.3$ & $1.0 \pm 0.5$ & $0.9 \pm 0.4$ \\
\hline
\end{tabular}

${ }_{1}^{1}$ RDA: Belgian Recommended Daily Allowances (4)

${ }^{2} \mathrm{M}$ : male; F: female

Group 3 - college students

In the college students, mean total energy intake for vegetarians and omnivores did not reach the reference value (Table 2). For the vegetarians mean macronutrient distribution was within the recommended values (Table 2). In the omnivores the carbohydrate intake $(46 \pm 6 \mathrm{E} \%)$ was too low and the fat intake $(35 \pm 5 \mathrm{E} \%)$ too high.

The fibre intake was significantly higher $(p=0.007)$ in the vegetarians $(15 g / 4.2 \mathrm{MJ})$ compared to the non-vegetarians $(9 \mathrm{~g} / 4.2 \mathrm{MJ})$. Analysis of vitamin intake (A, B1, B2, B6, C) indicated a significant $(p<0.05)$ lower intake of vitamin $B 6$ only in the male vegetarians $(1.32 \pm 0.42$ $\mathrm{mg} /$ day) than their non-vegetarian counterparts $(1.78 \pm 0.47 \mathrm{mg} /$ day) $(16)$. The mean B6 intake of the male vegetarian subjects was below the recommended intake (RDA $1.7 \mathrm{mg} / \mathrm{day}$ ).

Analysis of the mineral intakes (calcium, phosphorus, magnesium, sodium, potassium, iron, haem-iron and zinc) (16) showed significantly lower intake of iron in the male vegetarians $(13.6 \pm 4.8 \mathrm{mg} / \mathrm{day})$ than their non-vegetarian counterparts $(16.9 \pm 3.8 \mathrm{mg} / \mathrm{day})(p<0.05)$. Nevertheless, the intakes of both groups were above the reference value of $9.0 \mathrm{mg} / \mathrm{day}$. Iron intake of the female vegetarians $(10.9 \pm 4.1 \mathrm{mg} /$ day $)$ was comparable with the female nonvegetarians $(11.5 \pm 3.9 \mathrm{mg} / \mathrm{day})$. This intake is far below the recommended values of $20 \mathrm{mg} /$ day for non-menopausal women (4). The contribution of haem-iron in the vegetarians 
(males and females together) was $0.27 \pm 0.29 \mathrm{mg} /$ day versus $5.21 \pm 1.84 \mathrm{mg} / \mathrm{day}$ in the nonvegetarians. Zinc intake was significantly lower $(p<0.001)$ in the male vegetarians $(6.5 \pm 3.0$ $\mathrm{mg} /$ day) than in the male omnivores $(11.6 \pm 30 \mathrm{mg} /$ day $)$. There was no significant difference in zinc intake between $(p>0.05)$ female vegetarians $(4.2 \pm 1 \mathrm{mg} /$ day $)$ and the female nonvegetarians $(7.6 \pm 2 \mathrm{mg} /$ day $)$. All males and females had a mean zinc intake below the reference value (4).

The blood profile indicated significantly $(p<0.05)$ lower vitamin $B 12$ values in the vegetarians $(0.24 \pm 0.08 \mu \mathrm{g} / \mathrm{dl})$ compared to the non-vegetarians $(0.31 \pm 0.14 \mu \mathrm{g} / \mathrm{dl})$. Mean values of both groups were near the lower limit of the standard reference $(0.17-0.94 \mu \mathrm{g} / \mathrm{dl})$. The low iron and zinc nutritional intakes were not fully reflected in the blood profile. However, iron and zinc were within the reference limits, and only for ferritin significantly $(p<0.05)$ lower values were found for the male vegetarians (mean value $50 \pm 19 \mu \mathrm{g} / \mathrm{l}$ ) compared to the non-vegetarians $(73 \pm 29 \mu \mathrm{g} / \mathrm{l})$, (reference value: 18.7 to $323 \mu \mathrm{g} / \mathrm{l})$. The ferritin values were not significantly different $(p=0.058)$ when comparing the female vegetarians $(22 \pm 12 \mu \mathrm{g} / \mathrm{l})$ and non-vegetarians $(51 \pm 15 \mu \mathrm{g} / \mathrm{l})$ (reference value: 6.9 to $282 \mu \mathrm{g} / \mathrm{l})(16)$.

\section{Group 4 - lifelong vegetarians}

In the lifelong vegetarians (Group 4), mean total energy intake reached the reference value (taking into account their individual age-related requirements) in males and females (Table 2). The macronutrient distribution indicated that the protein contribution was within the recommendations while the carbohydrate contribution was too low and the fat contribution too high (Table 2).

Protein intake was below the minimal RDA for 4 subjects while another 4 had an intake above the maximal RDA. Only 11 subjects met the carbohydrate reference while only 10 subjects did not exceed the maximal RDA for fat (17).

Mean cholesterol intake was $176 \pm 103 \mathrm{mg}$ (maximal allowed intake of $300 \mathrm{mg} / \mathrm{day}$ ). Fibre intake was well within the recommended values. Mean intake of vitamins $A, B 1$, and C were all above the recommended reference values for men and women. Mean vitamin B2 intake of the men $(1.56 \pm 0.70 \mathrm{mg} /$ day $)$ did not reach the RDA (1.60 mg/day). As to vitamin B6 neither men (mean intake $1.18 \pm 0.69 \mathrm{mg} /$ day) nor women (mean intake $0.80 \pm 0.26 \mathrm{mg} /$ day) reached the reference value $(1.70 \mathrm{mg} /$ day in men and $1.20 \mathrm{mg} /$ day in women). Mean sodium intake was slightly above the upper limit of the RDA in men only (mean intake: $3621 \pm 1297 \mathrm{mg} / \mathrm{day}$; reference values: $575-3500 \mathrm{mg} / \mathrm{day}$ ). This was also the case for potassium intake in males (mean intake: $3892 \pm 1945 \mathrm{mg} /$ day) and in females (3170 $\pm 899 \mathrm{mg} /$ day), (reference values for men and women: 1600-3100 mg/day). Mean calcium intake was above the upper RDA limit of $1200 \mathrm{mg} /$ day in men only (mean intake: $1244 \pm 855 \mathrm{mg} /$ day). Phosphorus intake was above the reference value (800-1000 mg/day) in men (mean intake $1648 \pm 544 \mathrm{mg} / \mathrm{day}$ ) and in women (mean intake1523 $\pm 698 \mathrm{mg} /$ day). The male subjects had a mean iron intake of $15.9 \pm 8.1 \mathrm{mg} /$ day (reference value $9 \mathrm{mg} /$ day). Mean iron intake in the females was low (13.1 $\pm 4.7 \mathrm{mg} /$ day) compared to the RDA of $20 \mathrm{mg} /$ day in pre-menopausal women. The meno- 
pausal women $(n=4)$ had a similar intake $(14.4 \pm 2.7 \mathrm{mg} /$ day $)$, which is above the recommended intake (reference value $8 \mathrm{mg} /$ day). Mean zinc intake was far under the RDA in men (mean intake: $5.0 \pm 3.1 \mathrm{mg} /$ day) and in women (mean intake: $4.0 \pm 1.4 \mathrm{mg} /$ day) since the RDA values are respectively 15 and $12 \mathrm{mg} /$ day. Blood profile was analysed for the following variables: vitamin B12, vitamin B9, iron, cholesterol, LDL-cholesterol, calcium, zinc, ferritin, and transferrin. Mean values of these different blood parameters were all within the normal limits (17).

Group 5 - adults

In Group 5 energy intake did not meet energy expenditure. The macronutrient distribution was within the recommended percentages (Table 2).

Cholesterol intake was low in men (mean intake $139 \pm 102 \mathrm{mg} /$ day) and in women (113 \pm 88 $\mathrm{mg} / \mathrm{day}$ ), and only 2 men and 3 women had an intake above the maximal allowance of $300 \mathrm{mg} /$ day.

Fibre intake was high and the values in men ( $35 \pm 13 \mathrm{~g} /$ day) and women ( $32 \pm 13 \mathrm{~g} /$ day) were far above the recommended minimal intake (respectively $26 \mathrm{~g} /$ day in the men and $19 \mathrm{~g} /$ day in the women). Mean calcium intake was above the recommended $(900 \mathrm{mg} /$ day) intake in both sexes (respectively $968 \pm 451 \mathrm{mg} /$ day in the men and $964 \pm 374 \mathrm{mg} /$ day in the women).

Iron intake was above the RDA of $9 \mathrm{mg} /$ day in the men (mean intake $16 \pm 6 \mathrm{mg} /$ day). The mean iron intake in the women was $14 \pm 6 \mathrm{mg} / \mathrm{day}$. The latter value is under the recommended intake of $20 \mathrm{mg} /$ day for pre-menopausal women, but above the minimal intake (8mg/day) for post-menopausal women.

Zinc intake was below the minimal recommended intake in men (mean intake 9.2 $\pm 3.7 \mathrm{mg} /$ day, recommended intake $15 \mathrm{mg} / \mathrm{day}$ ) and in women (mean intake $8.3 \pm 3.0 \mathrm{mg} /$ day, recommended intake $12 \mathrm{mg} /$ day).

Due to incomplete food databases the Becel software indicated reliable data for a limited number of vitamins only. Mean intake of vitamins A $(846 \pm 427 \mu \mathrm{g} / \mathrm{day})$ and $C(110 \pm 98$ $\mu \mathrm{g} /$ day) was above the recommended minimal intake.

Vitamin B1 and B2 intakes were low whereas vitamin B6 intake was within the recommended limits. Mean vitamin B12 intake was below the recommended intake limit of $1.4 \mu \mathrm{g} / \mathrm{day}$ (mean intake value $1.03 \pm 0.77 \mu \mathrm{g} / \mathrm{day}$ ). Only $30 \%$ of the subjects reached this recommended intake limit.

\section{Discussion}

Mean total energy intake reached the reference values in the group of lifelong vegetarians (Group 4) only. This is a point of concern, especially in the youngest subjects (Group 1) where 11 out of the 27 young children did not reach the $80 \%$ tolerance of total energy intake. Macronutrient analysis reveals that energy density of the consumed diet is rather low as indicated by the number of subjects not reaching the lower limit for fat intake (12 out of 27), and 
the number of subjects (26 out of 27 ) exceeding the $120 \%$ tolerance limit for carbohydrate intake. Also, in Group 2 the low values for total energy intake are a matter of concern since a substantial number of subjects from that group is in their growth and development phase (20). This is in agreement with recent published data by Newby (23) and may explain the reported delayed maturing process in vegetarian children with a catch-up during adolescence (18). In the study where a comparison with 'matched pairs' was used (Group 3), a lower total energy intake was noticed in the male vegetarian students compared to their non-vegetarian counterparts (16). In Group 5 where energy expenditure was calculated on an individual basis, a caloric deficit was also found. Our values on caloric intake of adult vegetarian subjects (Groups 2 and 3) are in agreement with those of the lacto-ovo-vegetarian subjects studied in France (14); the mean intake in the latter study being $2384 \mathrm{kcal} /$ day $(10.0 \mathrm{MJ} / \mathrm{day})$ in males and $1675 \mathrm{kcal} /$ day $(7.0 \mathrm{MJ} /$ day $)$ in females. According to these authors the energy intake values were below the RDA of that country, but comparable with other surveys on omnivorous subjects (14). The vegetarians in the EPIC-Oxford study had a mean energy intake of respectively $8.78 \pm 2.39 \mathrm{MJ}$ in men and $7.60 \pm 2.10 \mathrm{MJ}$ in women (12), which corroborates the reported intakes in our studies. The meat-eaters in that study had a higher caloric intake compared to the vegetarians (respectively $9.18 \pm 2.46 \mathrm{MJ}$ in the men and $8.02 \pm 2.11 \mathrm{MJ}$ in the women) (12). This was not the case in our study since adult energy intake data were very close to the values of the most recent national survey with energy intake values for a representative sample of the omnivorous population of respectively $2465 \mathrm{kcal} /$ day $(10.3 \mathrm{MJ} /$ day $)$ in males and $1648 \mathrm{kcal} /$ day (6.9MJ/day) in females (2).

The mean macronutrient distribution in the different Flemish vegetarian groups studied (Table 2) was closer to the food based dietary guidelines (3) than the distribution observed in the most recent national survey (2). Protein contribution was within the limits in all vegetarian groups studied. With a mean carbohydrate contribution of $51 \pm 7.4 \mathrm{E} \%$ only the lifelong vegetarians did not reach the lower limit of $55 \mathrm{E} \%$. That was also the group with the highest contribution of fat $(34 \pm 8 \mathrm{E} \%)$ to the total energy intake. The distribution of the macronutrient intake in the lifelong vegetarians is in agreement with the findings in French vegetarians (14). In contrast, our other vegetarian groups studied (Groups 1, 2, 3 and 5) had a carbohydrate intake above the contribution reported in most of the studies $(11,12,14)$, but lower than the values obtained in Swedish lacto-vegetarian women where carbohydrate contributed $59.8 \pm 0.5 \mathrm{E} \%$ of total energy intake (15). In that particular study the intake of fat was very low $(25.2 \pm 0.4 \mathrm{E} \%)$ compared to our groups and to the other studies $(11,12,14)$.

The combination of a lower energy intake with a balanced macronutrient distribution may result in a healthier weight status. Indeed, we found lower BMI values in the Flemish vegetarians than in the Belgian reference population $(2,21)$, which is in agreement with the literature $(12,15,23)$.

Mean cholesterol intake was always under the maximal allowed intake of $300 \mathrm{mg} / \mathrm{day}$. Intakes varied from $113 \mathrm{mg} /$ day in the females of the adult study (Group 5) to $180 \mathrm{mg} /$ day in the vegetarian college students (Group 3). In the latter study, the non-vegetarian students had a 
mean intake $(303 \pm 175 \mathrm{mg} / \mathrm{d})$ above the maximal allowed intake. In all the groups studied the vegetarian subjects had fibre intakes exceeding the recommended quantities.

The adequacy of a vegetarian diet for the minerals calcium, iron and zinc is often questioned. Our data show in all adult groups (except Group 2) a mean calcium intake above the minimal recommended intake of $900 \mathrm{mg} / \mathrm{day}$. Our data corroborate the calcium intake data obtained in the EPIC-Oxford study where calcium intakes of respectively $1087 \pm 408 \mathrm{mg} / \mathrm{day}$ are reported for men and $1012 \pm 356 \mathrm{mg} /$ day for women (12). In contrast, the intake for the general Belgian population as reported in the most recent nutritional survey was respectively for men 833 $\mathrm{mg} /$ day and for women $714 \mathrm{mg} /$ day (2). Mean iron intake was sufficient in all male subjects studied. In the female subjects mean iron intake did not reach the recommended intake of $20 \mathrm{mg} /$ day for pre-menopausal women (4). In most of the groups studied we found low zinc intakes. However, these low iron and zinc intakes were not reflected in the blood values, where individual values were never below the lower reference limit $(16,17)$. Additionally, the obtained quantities for iron and zinc are comparable to those reported in the EPIC-Oxford study (12).

Analysis of vitamins in the different groups studied is more complex. Data on vitamin content are poor in the NUBEL food composition table (22) which is used by the BECEL nutrition analysis programme. As a consequence, results on vitamins are often indicated as incomplete and the results need to be interpreted with utmost caution. In the vegetarian groups studied, low intakes were found for vitamins B2 and B6 while intakes of vitamins A and C were high, whereas vitamin B12 is not always comprised in the BECEL nutrition analysis programme. Although the blood analyses indicated that mean vitamin B12 values were within the reference values in Group 3 and 4, we detected 3 subjects with vitamin B12 blood concentrations beneath the reference value (respectively $0.104,0.114$ and $0.116 \mu \mathrm{g} / \mathrm{dl}$; ref.: $0.170-0.940 \mu \mathrm{g} / \mathrm{dl}),(16,17)$. Based on the analysis of the food diaries we may conclude that most $(98 \%)$ of the subjects studied were lacto-ovo-vegetarians. That type of vegetarians may receive considerable amounts of B12 from eggs and dairy products.

The nutritional intake of the different groups studied indicates that a vegetarian diet as consumed in Flanders can be appropriate for all the age groups studied. However, in every group a number of atypical cases was detected. Vegetarian meals - just like omnivorous meals - need to be well balanced and properly planned to be nutritionally adequate (24). Replacement of meat - which is the main protein and vitamin B12 source in the Flemish diet - with a meat analogue does not result per se in a healthier diet. Sufficient knowledge and information concerning wholesome vegetarian nutrition is required when adopting a vegetarian lifestyle.

The fact that data were derived from different studies with different designs is a drawback in the present survey. Further limitations of the present survey are the relatively small numbers of subjects in the different groups. Also, the self-selection of subjects imposed by the way of recruiting vegetarians may have attracted the more health conscious subjects, yielding a certain bias. However, we reported dietary data of a total of 243 subjects covering a wide range 
of age, including a unique group of 36 lifelong vegetarians. Follow-up studies are needed to evaluate long-term compliance with a vegetarian diet.

In conclusion, this overview provides valuable information on the nutritional intake of various vegetarian groups in the Flemish region of Belgium. Our data indicate that a vegetarian diet as consumed by the tested population may be adequate. However, the outliers showed that proper planning of a vegetarian diet is advisable.

Furthermore, this study contributes to a growing body of knowledge concerning the dietary and health aspects of vegetarians.

\section{References}

1. Khaw KT, Wareham N, Bingham S, Welch A, Luben R, Day N. Combined impact of health behaviours and mortality in men and women: the EPIC-Norfolk prospective population study. Open Acess. PLoS Medicine, www.plosmedicine.org January 2008 Volume 5 issue 1:39-47

2. Debacker N, Temme L, Cox B, Huybrechts I, Van Oyen H. De Belgische voedsel consumptie peiling 2004. Voedingsgewoonten van de Belgische bevolking ouder dan 15 jaar. (Belgian food consumption survey 2004. Nutritional habits of the Belgian population over 15 years of age) Wetenschappelijk Instituut voor Volksgezondheid, Afdeling Epidemiologie, Brussel 2007

3. Vandevijvere S, De Vriese S, Huybrechts I, Moreau M, Temme E, De Henauw S, De Backer G, Kornitzer $\mathrm{M}$, Leveque $\mathrm{A}$, Van Oyen $\mathrm{H}$. The gap between food-based dietary guidelines and usual food consumption in Belgium, 2004. Public Health Nutrition, 2008, 12(3):423-31

4. Hoge Gezondheidsraad (Higher Health Council). Voedingsaanbevelingen voor België (Nutritional recommendations for Belgium) nr. 7145-2. Brussel 2006

5. Knoops KT, de Groot LC, Kromhout D, Perrin A-E, Moreiras-Verela O, Menotti A, van Staveren WA. Mediterranean diet, lifestyle factors, and 10-year mortality in elderly European men and women. The HALE project. JAMA 2004; 292 no.12:1433-9

6. Trichopoulou A, Orfanos P, Norat T, Bueno-de-Mesquita B, Ocké M et al. Modified Mediterranean diet and survival: EPIC-elderly prospective cohort study. BMJ 2005; 330; 991

7. Bamia C, Trichopoulos D, Ferrari P, Overvad K, Bjerregaard L, et al. Dietary patterns and survival of older Europeans: the EPIC-elderly study (European Prospective Investigation into Cancer and Nutrition). Publ Hlth Nutr 2007; 10(6):590-8

8. Mullie P, Clarys P, De Ridder D, Deriemaeker P, Duvigneaud N, Hebbelinck M, Grivegnée AR, Autier P. Breakfast frequency, and fruit and vegetable consumption in Belgian adolescents: a cross-sectional study. Nutr \& Food Sc 2006; 36 (5):315-26

9. Chang-Claude $\mathrm{J}$ and Frentzel-Beyme. Dietary and lifestyle determinants of mortality among German vegetarians. Int J Epidem. 1993; 22 (2): 228-36

10. Sanders TAB, Reddy S. Vegetarian diets and children. Am J Clin Nutr 1994; 59 (suppl):1176S-81S

11. Nathan I, Hackett AF, Kirby S. The dietary intake of a group of vegetarian children aged 7-11 years compared with matched omnivores. Brit J of Nutr 1996; 75:533-44

12. Davey GK, Spencer EA, Appleby PN, Allen NE, Knox KH, Key TJ. EPIC-Oxford: lifestyle characteristics and nutrient intakes in a cohort of 33883 meat-eaters and 31546 non meat-eaters in the UK. Publ HIth Nutr 2003; 6(3):259-68

13. Key TJ, Fraser GE, Thorogood M, Applby PN, Beral V, Reeves G, Burr ML, Chang-Claude J, FrentzelBeyme R, Kuzma JW, Mann J, and McPherson K. Mortality in vegetarians and nonvegetarians: detailed findings from a collaborative analysis of 5 prospective studies. Am J Clin Nutr 1999; 70 (suppl):516S-24S

14. Leblanc JCh, Yoon $\mathrm{H}$, Kombadjian A, Verger Ph. Nutritional intakes of vegetarian populations in France. Eur J of Clin Nutr 2000; 54:443-9 
15. Newby PK, Tucker KL, Wolk A. Risk of overweight and obesity among semivegetarian, lactovegetarian, and vegan women. Am J Clin Nutr 2005; 81:1267-74

16. Clarys $P$, Deriemaeker $P$, Hebbelinck $M$. Study of physical fitness and health related parameters in vegetarian and non-vegetarian students. Nutr \& Food Sc 2000; 30(5):243-9

17. Clarys $P$, Deriemaeker $P$, Hebbelinck $M$, Bosmans $D$, Bertier $B$. Physical fitness and health-related parameters in Flemish life-long vegetarians: a pilot study. Nutr \& Food Sc 2004; 34 (1):29-41

18. Hebbelinck $M$ and Clarys $P$, Physical growth and development in vegetarian children and adolescents. in Sabaté J, ed. Vegetarian Nutrition. Boca Raton, FI: CRC Press; 2001; 173-93

19. Lauwers L. Inleiding tot de baby- en kindervoeding. (Introduction to baby- and child nutrition) Leuven: Acco, 1993

20. Hebbelinck M, Clarys P, De Malsche A. Growth, development, and physical fitness of Flemish vegetarian children, adolescents, and young adults. Am J Clin Nutr 1999; 70 (suppl): 579S-85S

21. Alewaeters K, Clarys P, Hebbelinck M, Deriemaeker P, Clarijs J.P. Cross-sectional analysis of BMI and some lifestyle variables in Flemish vegetarians compared with non-vegetarians. Ergonomics 2005; 48:1433-44

22. NUBEL (1996 to 2004) Belgische Voedingsmiddelentabel (Belgian nutrient table), NUBEL, Brussels

23. Newby PK. Plant foods and plant-based diets: protective against childhood obesity? Am J Clin Nutr 2009: 89 (suppl) :1572S-87S

24. Position of the American Dietetic Association: Vegetarian Diets. J Am Diet Assoc. 2009;109:1266-82 